\title{
ENSINO DE ALGORITMOS APOIADO PELO USO DE JOGOS DIGITAIS EDUCATIVOS
}

\author{
Marcelo de Souza, CEAVI - UDESC \\ bsi.marcelo@gmail.com \\ Eliana Vogel Jaeger, CEAVI - UDESC \\ eliana@ibnet.com.br \\ Brigiane Machado da Silva Cardoso, CEAVI - UDESC \\ brigianemachado@gmail.com
}

\begin{abstract}
Resumo. Atualmente se percebe uma crescente dificuldade no aprendizado de lógica de programação nos cursos superiores de computação. Para auxiliar na aprendizagem do tema, metodologias diferenciadas de ensino são estudadas. Uma metodologia que vem se apresentando eficaz e com bons resultados consiste na aplicação de soluções lúdicas de ensino. Com base nesse panorama, o presente trabalho apresenta o desenvolvimento e aplicação de um jogo na resolução de um algoritmo para um popular problema lógico. O jogo busca identificar os benefícios trazidos pela sua aplicação no aprendizado de conceitos de lógica de programação com uma turma de Algoritmos. Para isso, o jogo foi aplicado durante a construção de um algoritmo para o problema da travessia do rio. Como resultados, foi possível identificar a facilidade trazida pelo jogo na construção da solução, esclarecimento de aspectos do problema e a criação de um ambiente desafiador e estimulante para os acadêmicos.
\end{abstract}

Palavras-chave: Jogos, algoritmos, lúdico.

\section{TEACHING ALGORITHMS SUPPORTED BY THE USE OF EDUCATIONAL DIGITAL GAMES}

Abstract. Currently, one perceives a growing difficulty in learning programming logic in courses of Computing in higher education. To assist them in the learning of the subject, differentiated teaching methodologies are studied. A methodology that has been performing effectively and with good results consists in applying playful learning solutions. Based on this scenario, this paper presents the development and application of a game in the resolution of an algorithm for a popular logical problem. The game aims to identify the benefits brought by its application in learning concepts of logic programming with a class of algorithms. For this reason, the game has been applied during the construction of an algorithm to the problem of crossing river. As result, it was possible to identify the facility brought the game to build the solution, clarifying aspects of the problem and creating a stimulating and challenging environment for students.

Key-words: Games, algorithms, playful.

\section{1 - Introdução}

O raciocínio lógico é uma habilidade com exigência crescente nas mais diversas áreas do conhecimento. Em cursos superiores é comum encontrar disciplinas que abordem o tema, lógica. Em cursos de áreas como tecnologia e engenharia, a temática lógica apresenta grande dificuldade de assimilação por parte dos acadêmicos. Esse 
panorama resulta nos altos índices de reprovação e evasão. Quando se trata de cursos na área da computação, essa dificuldade se concentra sobretudo no aprendizado de programação. Nesses cursos, a lógica de programação é um importante instrumento na criação de algoritmos e programas de computador, tornando-se uma habilidade essencial aos acadêmicos. Entretanto, muitos acadêmicos encontram dificuldades no seu aprendizado. Tem-se verificado que esse cenário constitui-se de um dos grandes motivos de evasão escolar nos cursos de computação (Rocha et al., 2010). De modo geral, os acadêmicos não apresentam desenvoltura em pontos importantes, como organização de raciocínio, elaboração de estratégias, resolução de problemas e concentração, comprometendo habilidades como tentativa e erro, observação, dedução e desenvolvimento do raciocínio lógico (Tarouco e Berch, 2009).

Essa dificuldade está presente desde as disciplinas iniciais do curso, o que faz com que muitos acadêmicos não possam avançar. É o caso das disciplinas que trabalham o estudo e desenvolvimento de algoritmos. Algoritmos são sequências lógicas para resolução de um problema, essa sequência é traduzida para uma linguagem de programação, de modo que o computador possa executar esse algoritmo. Docentes destacam que a dificuldade de ensinar algoritmos se dá pelo fato dos acadêmicos não conseguirem elaborar essa sequência lógica (Tarouco e Berch, 2009). Frente à ineficiência dos modelos tradicionais de ensino para o aprendizado de lógica, os jogos educativos surgem como um meio que, de forma lúdica e desafiadora, estimulam o aluno na resolução dos problemas propostos pela disciplina. A utilização de jogos, portanto, pode auxiliar os acadêmicos no desenvolvimento das habilidades necessárias para a construção de algoritmos.

O presente trabalho objetiva identificar a eficácia da utilização de estratégias lúdicas no ensino de lógica de programação. Isto é, perceber as contribuições da aplicação de um jogo em determinado problema lógico, verificando se houve uma melhora no desempenho dos acadêmicos e a diminuição da dificuldade na sua resolução. Para isso, foi realizada uma experimentação com um grupo de acadêmicos da disciplina de Algoritmos do curso de Bacharelado em Sistemas de Informação da Universidade do Estado de Santa Catarina. Foi proposto um desafio lógico, a partir do qual os acadêmicos deveriam desenvolver um algoritmo. Aplicando um jogo que implementa o desafio proposto, foram identificados os impactos da nova metodologia no desempenho dos acadêmicos.

Este artigo está dividido em sete seções. Esta seção aborda a introdução para o trabalho. A seção 2 apresenta os materiais e métodos de pesquisa utilizados. A seção 3 apresenta a fundamentação teórica a respeito de jogos educativos digitais e introduz a aplicação dos mesmos no ensino de algoritmos, objeto de estudo do presente artigo. A seção 4 traz alguns trabalhos correlatos ao presente artigo, detalhando seu desenvolvimento e resultados. Na seção 5 é abordada a experimentação realizada, bem como o jogo desenvolvido para aplicação. Por fim, a seção 6 apresenta os resultados da experimentação, enquanto a seção 7 contempla as conclusões do trabalho.

\section{2 - Materiais e métodos}

A pesquisa é classificada do ponto de vista da abordagem como quantitativa, pois conforme considera Gil (2008), as opiniões podem ser traduzidas em números, para então classifica-las e analisá-las. Adota-se uma postura quantitativa com os dados levantados e tabulados, por pretender numerar e medir. Quanto ao ponto de vista dos objetivos, a pesquisa é classificada como descritiva, pois procura basicamente descrever o objeto de estudo, destacando suas características e identificando as relações existentes entre os fatores envolvidos. A pesquisa ainda pode ser classificada quanto aos 
procedimentos técnicos, segundo Gil (2008), como um levantamento, pois envolve a interrogação direta de pessoas cujos conceitos têm-se necessidade de identificar. A população que foi interrogada foi um grupo de acadêmicos do Centro de Educação Superior do Alto Vale do Itajaí - SC, com uma turma de Algoritmos. A técnica utilizada foi um questionário com nove perguntas fechadas.

A população foi escolhida com base na necessidade dos acadêmicos de diferentes metodologias de ensino. Essa necessidade parte da dificuldade apresentada pelo grupo na assimilação dos conteúdos, uma vez que se trata de uma turma paralela de algoritmos para estudantes que não obtiveram êxito em tentativas anteriores de aprovação. A aplicação do jogo como instrumento de ensino se deu no mês de outubro de dois mil e treze.

\section{3 - Jogos educativos digitais e a proposta de aplicação no ensino de algoritmos}

$\mathrm{O}$ aprendizado de forma lúdica já existe há centenas de anos, através de contos e fábulas contadas aos mais novos no sentido de lhes transmitir ideias e conhecimento. $\mathrm{Na}$ história recente, este método evoluiu para outros formatos, como programas de televisão e jogos digitais (Gonçalves, 2011). Segundo Correia et al. (2009), um jogo digital pode ser compreendido como qualquer aplicação onde exista um sistema formal de ganhos, perdas, utilidades, estratégias e funções. Além dessas características, um jogo digital é desenhado para ser utilizado em algum dispositivo tecnológico como computador, tablet ou celular, no qual exista interação entre humano e tecnologia. Na visão de Gonçalves (2011), jogos digitais educativos tratam da educação através do entretenimento. Ou seja, o desenvolvimento da aprendizagem enquanto se pratica uma atividade de caráter lúdico. De acordo com o autor, deve-se tomar o cuidado em manter sempre presente o objetivo do aprendizado.

É comum a utilização de jogos para o estímulo da aprendizagem, tornando-os uma ferramenta bastante utilizada por pedagogos. Neste sentido, já é consenso a afirmativa acerca da efetividade dos mesmos na aprendizagem (Páris, 2008). Segundo Grübel e Bez (2006), o jogo educativo é uma abordagem que facilita o ensino e a aprendizagem de um determinado assunto, sendo um rico instrumento para a construção do conhecimento. Sampaio (2013) trata do valor educativo de um jogo como a motivação envolvida no ato de jogar, progredir, liderar e assimilar conceitos. Essa motivação leva o jogador à imersão na aplicação e no seu contexto. Mendes (2011) reforça que os fatores que contribuem para que jogos educativos digitais cumpram com seu papel são os grandes desafios que quem os utilizar vai encontrar, bem como os estímulos sensoriais, a qualidade e a aprendizagem envolvida. Todos esses aspectos são fatores que levarão a um ensino de qualidade.

As vantagens na utilização de jogos digitais como ferramenta de aprendizagem são várias. Segundo Mendes (2011), jogos digitais usam alternativas lúdicas para aplicar o ensino, exigindo o desenvolvimento de habilidades como a destreza motora, a tomada de decisão e a persistência. Com essas habilidades mais presentes no aprendizado ocorre uma compreensão mais profunda do tema. Mendes (2011) aborda o fato dos jogos levarem o aluno a obter informações que se combinam com a diversão e lazer, fazendo com que se torne mais atrativo em relação às metodologias tradicionais de ensino. Em suma, um jogo cognitivo eletrônico consiste em um software onde são propostos desafios, os quais exigem a utilização de aspectos cognitivos como memória, raciocínio e atenção. Esses jogos são apresentados em diferentes formatos e, de maneira geral, são aplicações simples e permitem sua utilização na resolução de um problema. Neste sentido, apresentam-se como importante meio de suporte para a obtenção da solução de um exercício. (Ramos, 2013). 
Uma vez que a aplicação de jogos como instrumento lúdico de ensino e aprendizagem tem crescido e se apresentado eficaz, o presente trabalho apresenta uma proposta de ensino de lógica por meio de jogos. Para isso, foi desenvolvido um jogo baseado no problema da travessia do rio, um desafio lógico bastante pertinente para o ensino de algoritmos e lógica de programação. Após seu desenvolvimento, o jogo foi aplicado a uma turma da disciplina de Algoritmos da Universidade do Estado de Santa Catarina, com o objetivo de avaliar os impactos e benefícios trazidos pela nova metodologia no aprendizado dos acadêmicos. A turma escolhida carece de estratégias diferenciadas para a abordagem do conteúdo, uma vez que possui dificuldades com a assimilação dos conceitos e desenvolvimento do raciocínio lógico.

\section{4 - Trabalhos relacionados}

Os jogos educativos digitais proporcionam um ambiente simulado onde o aluno pode experimentar as alternativas à solução de um problema e verificar suas consequências. Esta seção apresenta alguns trabalhos correlatos ao presente artigo. Nesses trabalhos, os autores aplicam jogos em ambientes educativos, verificando sua eficácia no ensino-aprendizagem.

\section{1 - O Jogo Magu como estratégia pedagógica}

Neste trabalho é apresentado o jogo educativo chamado Magu (Rapkiewicz et al., 2006). O jogo foi desenvolvido por um grupo de alunas do curso de Especialização em Informática na Educação da Universidade Federal do Rio Grande do Sul. A aplicação aconteceu com uma turma de Algoritmos, onde foi observada uma melhoria na assimilação do conteúdo, frente aos métodos tradicionais. De acordo com Rapkiewicz et al. (2006), os acadêmicos se sentem desmotivados com o modelo atual de ensino.

O jogo consiste no problema dos litros, onde se deve desenvolver um algoritmo capaz de colocar seis litros de água em um vaso utilizando como instrumentos dois vasos, um com capacidade de 7 litros e outro de 5 litros. Para tal, são permitidas as seguintes ações: encher o vaso a partir de uma fonte do líquido, esvaziar um vaso e trocar o líquido de um vaso a outro. O feedback proporcionado pelo jogo leva o aluno a fazer uma nova tentativa, o que estimula o aprendizado por reforço e repetição. A Figura 1 apresenta a interface principal do jogo (Rapkiewicz et al., 2006).

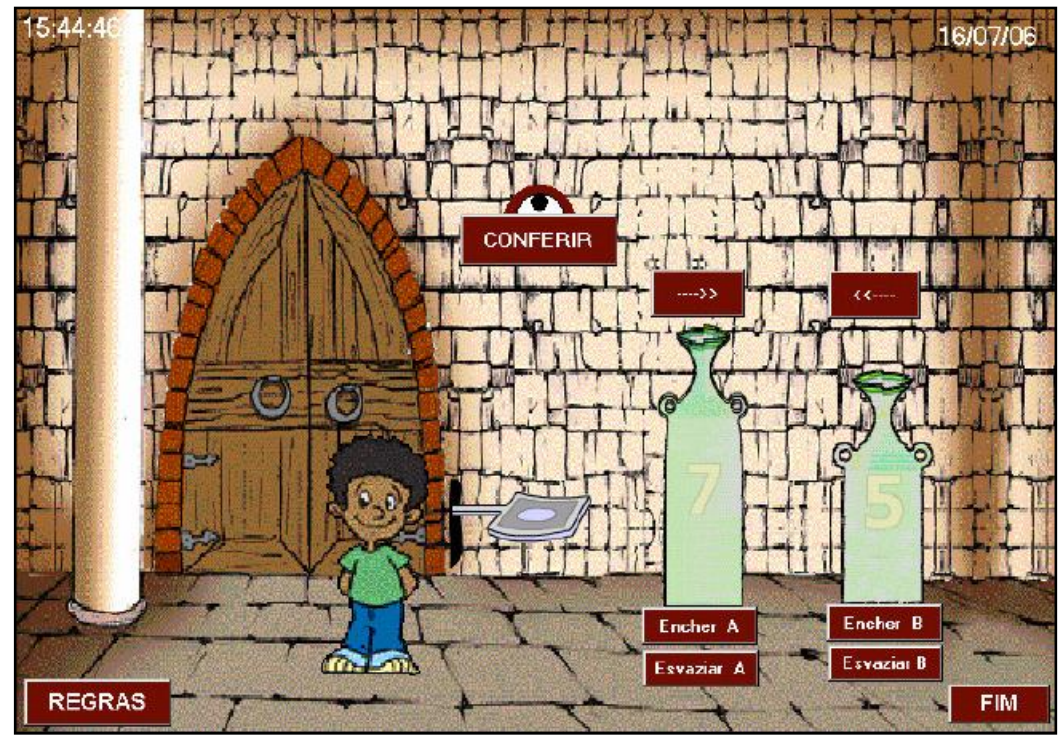

Figura 1 - Interface principal do jogo (Rapkiewicz et al., 2006) 
Como resultados do trabalho, concluiu-se que é possível utilizar o jogo para o aprendizado, objetivando o estímulo do raciocínio lógico. No entanto, a atuação do professor como o mediador das práticas e do aprendizado foi de grande importância para os resultados positivos.

\section{2 - Jogos no ensino de libras}

Neste trabalho, uma equipe da Universidade de Joinville realizou uma pesquisa experimental, na qual propuseram aos estudantes uma forma lúdica de aprendizado de libras. Para isso foi utilizado um jogo, proporcionando uma interação entre crianças com deficiência auditiva e ouvintes em um ambiente comum de aprendizagem. A pesquisa foi realizada junto às turmas de $1^{\mathrm{a}}$ a $5^{\mathrm{a}}$ série do Ensino Fundamental bilíngue da Escola Rui Barbosa de Joinville, que contou com cerca de 120 alunos ouvintes e 58 alunos deficientes. Além disso, também mediaram as experimentações os professores de cada disciplina, bem como intérpretes (Peixe et al., 2010).

Com auxílio de especialistas da área, como professores e profissionais que trabalham em contato com deficientes auditivos, foi desenvolvido o jogo educativo. Este jogo é constituído por um tabuleiro com duas fases, no qual as duplas devem ser mistas para propiciar a interação entre deficientes e ouvintes. No tema "zoológico" o objetivo do jogo é a alimentação dos animais. Estes estarão dispostos dentro de jaulas que não serão desenhadas, mas feitas em poliestireno e encaixadas no tabuleiro, para maior interação e atração visual. Cada um terá um personagem que poderá ser pintado antes de iniciar o jogo. No início do jogo, cada dupla ou equipe escolhe uma cor diferente e seis pacotes de comida, os quais deverão ser usados para alimentar os seis animais. Para ganhar alimento, é necessário responder algumas perguntas dispostas no tabuleiro. Ganha aquele que alimentar todos os animais primeiro (Peixe et al., 2010).

Para estimular o aprendizado, as perguntas são apresentadas em libras e em português, com desenhos e instruções. Deste modo, os ouvintes serão estimulados no aprendizado da linguagem de libras, assim como os deficientes auditivos terão seu vocabulário ampliado. Em suma, Peixe et al.(2010) abordam o fato do jogo não somente beneficiar o aprendizado de libras, mas do próprio português. A Figura 2 apresenta o desenho proposto pelo tabuleiro do jogo em questão.

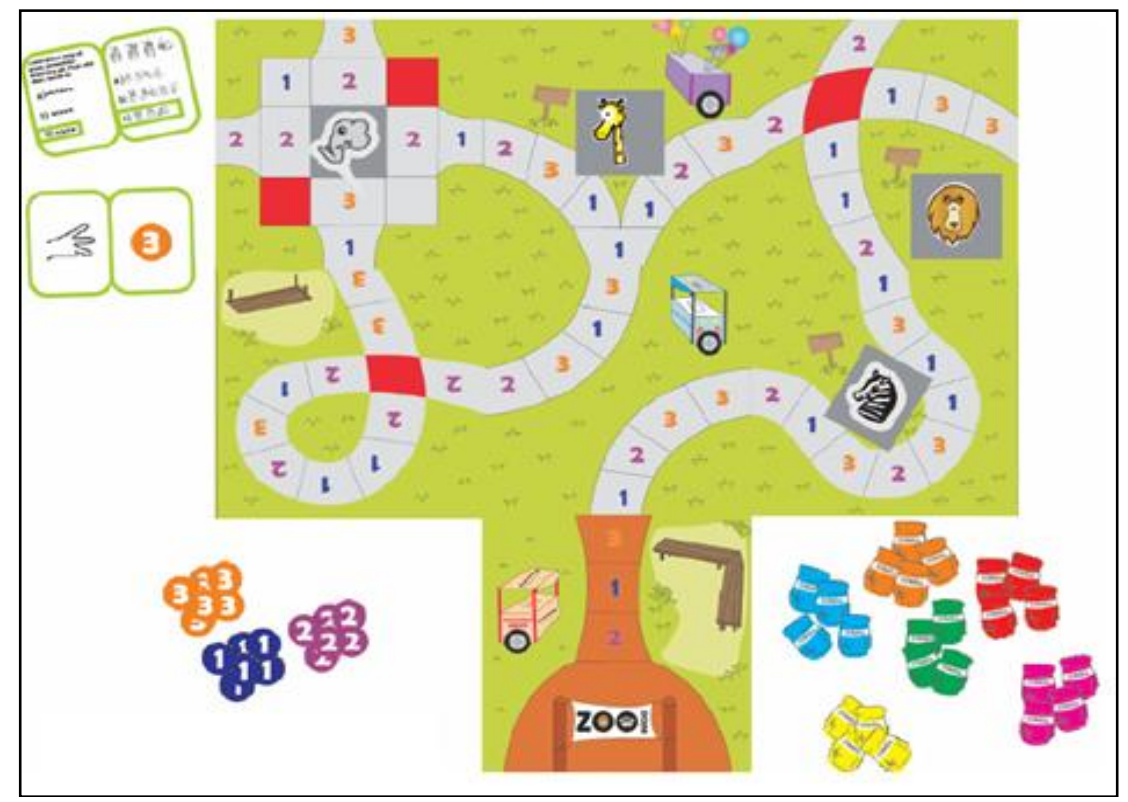

Figura 2 - Proposta de desenho para o tabuleiro (Peixe et. al., 2010) 
Com relação aos resultados, foi identificado que alguns aspectos do jogo precisam de ajustes, como os processos visuais e a representação das mensagens em libras, pois a interação entre deficientes e ouvintes ocorre de forma limitada. Apesar disso, o material lúdico se mostrou como fomentador de outras formas de interação, contribuindo na compreensão, tanto de linguagem de sinais como linguagem oral. Concluiu-se também que o material pode ser utilizado pelo professor como ferramenta de comunicação, expressão e aprendizado (Peixe et al., 2010).

\section{3 - Jogos no ensino de matemática}

Neste trabalho, um jogo educativo foi proposto para estimular a resolução de problemas matemáticos nas escolas. Neste intuito, uma equipe de acadêmicos do Centro de Informática de Pernambuco criou um jogo baseado na obra literária de Malba Tahan: o homem que calculava. De acordo com Barbosa Neto e Fonseca (2013), o problema proposto no jogo é a aventura vivida por Beremiz, personagem principal, onde o mesmo auxilia uma série de amigos a resolver problemas envolvendo matemática. Após finalizar o jogo, a aplicação ainda questiona acerca dos conceitos matemáticos aprendidos em sala de aula que foram usados para resolver o problema.

Após a aplicação de um questionário individual, percebeu-se que cerca de $88 \%$ entenderam rapidamente o que deveria fazer para interagir com o jogo e $87 \%$ conseguiram identificar os conteúdos ensinados em sala presentes na aplicação. Os resultados também comprovaram que a maioria instalaria o jogo e repassaria para seus amigos. Uma última constatação reside no fato dos alunos aprovarem o apoio à mobilidade na utilização de jogos para dispositivos móveis, tal qual a aplicação apresentada (Barbosa Neto e Fonseca, 2013). A Figura 3 apresenta um exemplo de interface da aplicação, na qual o jogador deve orientar os personagens em operações de divisão.

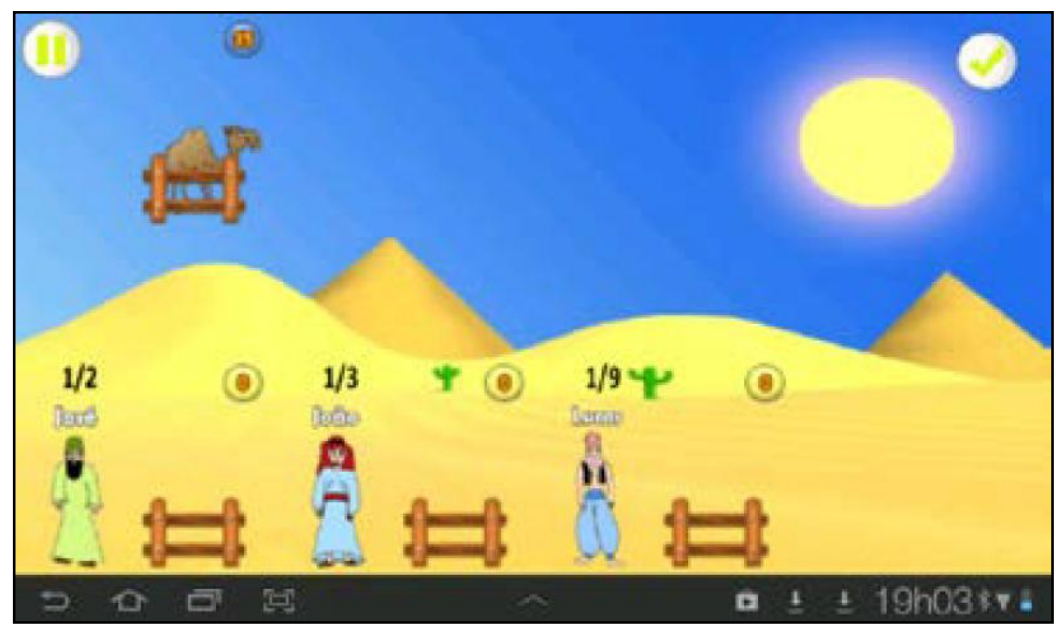

Figura 3 - Interface de jogo da aplicação Malba Tahan (Barbosa Neto e Fonseca, 2013)

\section{5 - Experimentação e o jogo desenvolvido}

O jogo é baseado no problema da travessia do rio, onde o jogador deve auxiliar um fazendeiro a atravessar seus pertences até a outra margem, respeitando algumas restrições. O fazendeiro possui uma raposa, uma ovelha e uma alface, podendo levar, a cada travessia a si mesmo e apenas um deles no barco. Se forem deixados sozinhos, isto é, sem o fazendeiro em uma mesma margem, a raposa come a ovelha e a ovelha come a alface. O objetivo, portanto, é fazer a travessia de todos os elementos sem nenhuma 
perda. Para isso, é necessária a construção de passos lógicos para o sucesso no problema.

O jogo foi desenvolvido utilizando HTML, CSS e JavaScript. Logo, é executado através de um navegador, estando disponível para qualquer plataforma. Na tela inicial, são apresentadas as opções de iniciar um novo jogo e instruções. Na opção instruções o usuário será informado sobre o problema a ser resolvido, enquanto a opção jogar o leva para a interface do jogo. Nesta última, o cenário é montado evidenciando o rio, suas margens, o barco e os personagens: fazendeiro, raposa, ovelha e alface, todos na margem esquerda do rio. Neste ponto também estão disponíveis ao jogador dois botões: o botão para levar os elementos até a outra margem e o segundo para reiniciar o jogo. Também é apresentado um quadro onde é dado um feedback ao usuário a cada ação realizada. Para jogar, o usuário deve selecionar os elementos que irão ao barco, clicando sobre os mesmos e clicar no botão "Ir ao outro lado". A Figura 4 apresenta a interface principal do jogo, onde o usuário pode experimentar todas as possibilidades de travessia.

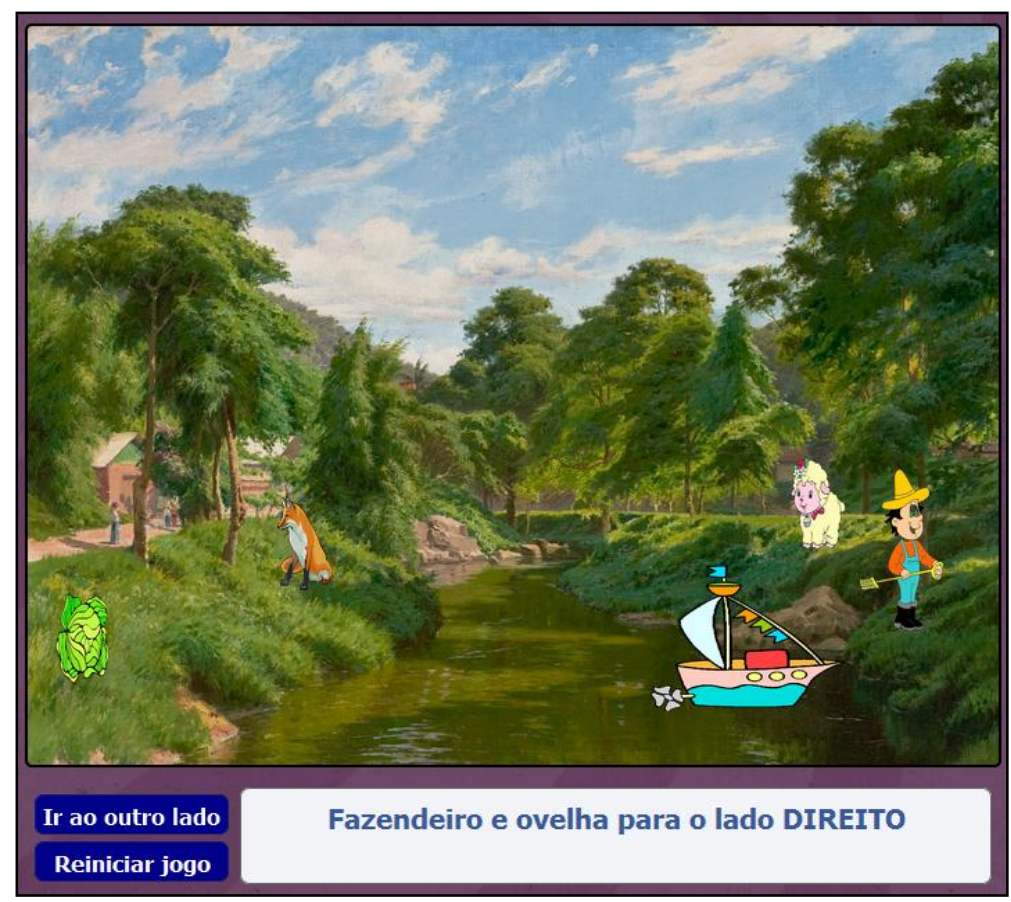

Figura 4 - Interface principal do Jogo do Fazendeiro

Como se pode perceber, para que o usuário logre êxito nas travessias e consiga chegar à solução do problema, é necessário que siga uma sequência lógica de passos. $\mathrm{O}$ mesmo panorama é encontrado na definição de algoritmos que, segundo Forbellone (1999), consiste em um conjunto de instruções para se chegar a determinado objetivo. Logo, o jogo se constitui como um possível instrumento de ensino e prática de algoritmos e lógica de programação. Neste sentido, o jogo foi aplicado a uma turma de Algoritmos, como instrumento para práticas de lógica de programação e suporte ao aprendizado dos temas pertinentes. A turma foi escolhida com base na dificuldade apresentada pelos acadêmicos no aprendizado de algoritmos.

A aplicação do jogo, com intuito de validar a eficácia do mesmo no aprendizado dos acadêmicos ocorreu no mês de outubro de dois mil e treze. Na oportunidade, foi proposto aos acadêmicos que desenvolvessem um algoritmo capaz de calcular e apresentar a sequência de travessias para a resolução do problema do fazendeiro, supracitado. Decorridos vinte minutos, foram registrados os avanços dos acadêmicos na 
sua resolução. Neste momento foi apresentado o Jogo do Fazendeiro, com o qual os acadêmicos puderam experimentar todas as possibilidades e observar, visualmente, os movimentos possíveis até chegar à solução. Novamente os acadêmicos tiveram vinte minutos para a resolução do exercício inicial, sendo registrados seus avanços no término deste tempo. Também foram analisadas as modificações produzidas no algoritmo após o contato com o jogo.

Ao final, os acadêmicos ainda responderam a um questionário individual, o qual buscou identificar as dificuldades do grupo e os pontos em que o jogo teve influência no aprendizado do tema. Para fins de análise, o exercício proposto e desenvolvido durante a aula exigiu duas habilidades principais: representar o conhecimento do tema e do estado dos personagens e implementar a lógica das travessias sucessivas.

\section{8 - Resultados e discussões}

Esta seção apresenta os dados coletados nos questionários e os resultados obtidos na aplicação do jogo em sala de aula. No questionário foi utilizada a técnica de escalonamento, com escala de coerência interna do tipo likert, buscando medir alguns aspectos em relação ao jogo aplicado. Esta técnica consiste em solicitar ao pesquisado que assinale a resposta que mais se aproxima com seus sentimentos em relação a cada afirmativa dentre um conjunto de alternativas (Rudolf, 2007), conseguindo medir o nível de satisfação dos acadêmicos. Utilizaram-se também perguntas fechadas e de múltipla escolha a fim de identificar se o jogo desenvolvido proporcionou algum benefício em relação ao desenvolvimento do algoritmo proposto.

Com relação ao grau de dificuldade, a turma apresenta dificuldade intermediária em entender os problemas de lógica propostos nas aulas (75\%), refletindo no número de vezes que está cursando a disciplina. De acordo com as respostas ao questionário, cerca de $75 \%$ dos acadêmicos já cursaram a disciplina anteriormente, sem sucesso, o que deixa evidente o grau de dificuldade de assimilação geral de problemas propostos.

A aplicação se deu em duas etapas principais. Na primeira, o professor explicou o problema de travessia do rio, propondo o desenvolvimento de um algoritmo com a lógica necessária para resolvê-lo. $\mathrm{Na}$ segunda etapa o jogo foi apresentado aos acadêmicos, os quais puderam visualizar o problema e experimentar todas as possibilidades de jogo. Após a apresentação da aplicação, os acadêmicos continuaram no desenvolvimento do exercício. Com relação aos aspectos gerais do jogo, os questionários apontam que todos os acadêmicos consideraram o jogo atrativo $\mathrm{e}$ interessante, com imagens razoavelmente claras e bom funcionamento. Ainda com base nos questionários, apenas um aluno conseguiu resolver o problema antes do contato com o jogo. Na segunda etapa, todos os acadêmicos lograram êxito no exercício proposto. Em resposta ao questionário, $100 \%$ dos acadêmicos afirmaram ter obtido algum benefício com a aplicação e o contato com o jogo.

Entre os benefícios apontados pelos acadêmicos com o ato de jogar e interagir com a aplicação desenvolvida estão alguns pontos em comum: compreensão da lógica de travessias $(50 \%)$, verificação do estado final de vitória ou derrota $(30 \%)$, forma representação do cenário $(50 \%)$ e representação do conhecimento $(20 \%)$. Além disso, cerca da metade dos acadêmicos afirmaram terem sido estimulados a resolver o problema através do jogo, bem como verificar todas as possibilidades e jogadas. $\mathrm{O}$ mesmo posicionamento é percebido com a opinião do professor que aplicou o jogo e propôs o exercício. Segundo este intermediador, a proposta lúdica gerou um interesse maior nos acadêmicos em trabalhar no exercício, criando um ambiente convidativo e desafiador. Através de um ambiente diferenciado, proporcionado pela nova metodologia, os acadêmicos demonstraram uma dedicação maior e, consequentemente, 
melhores resultados no trabalho proposto. Esse fator contribui diretamente para um aumento no aprendizado individual.

Ainda de acordo com respostas ao questionário e percepções do professor, a metodologia aplicada com a turma permitiu aos acadêmicos a visualização do problema sob uma nova ótica. Isto é, os acadêmicos puderam perceber visualmente aquilo que o algoritmo a ser desenvolvido deveria implementar. Com isso foi possível a percepção do cenário do problema, de novas restrições e situações na representação do estado dos personagens. Todos esses fatores contribuíram para um maior envolvimento com os conceitos de programação trabalhados em teoria e na proposta de exercício, gerando resultados positivos.

\section{9 - Conclusões}

Com base na experimentação realizada e nos resultados obtidos, detalhados em seções anteriores, foi identificada a eficácia da metodologia lúdica no aprendizado de lógica de programação. Conclui-se que a adoção de metodologias diferenciadas de ensino, por meio da exploração de estratégias lúdicas, contribui para uma melhora no aprendizado dos acadêmicos.

Essa melhora ocorre por muitos fatores. Os acadêmicos têm a possibilidade de visualizar a situação do problema e experimentar todas as possibilidades de ação. Com isso, são suprimidas dúvidas e os aspectos inerentes ao problema se tornam mais claros. Além disso, uma vez que o acadêmico tem a possibilidade de contato com o produto final do exercício, alguns conceitos se tornam evidentes. Na aplicação realizada, os alunos puderam melhor definir a forma de representação do estado dos personagens a cada movimentação, a lógica de trocas e suas restrições, bem como os estados de ganho ou perda. Uma vez percebidos estes aspectos, foi possível a aplicação dos conceitos de algoritmos e lógica de programação a fim de implementá-los. Neste sentido, conclui-se que os jogos são um importante e eficaz instrumento de ensino de algoritmos. Porém, deve ser utilizado como ferramenta auxiliar e complementar. Isto é, uma vez aprendidos os conceitos de lógica de programação, os jogos podem ser utilizados para a aplicação destes conceitos e solidificação dos conteúdos, bem como para esclarecimento de dúvidas.

Além da contribuição direta dos jogos como forma de aplicar os conceitos teóricos e solidificar os conhecimentos, foi identificado outro importante benefício. A utilização de estratégias lúdicas e de jogos em atividades de ensino cria um ambiente diferenciado de trabalho. Sua aplicação cria um ambiente prazeroso e desafiador, fazendo com que os acadêmicos apresentem uma vontade maior de resolução do exercício, resultando em um maior esforço. Este esforço extra contribui diretamente com ganhos no aprendizado. Em suma, conclui-se que a utilização de jogos em um ambiente de ensino de lógica de programação contribui para um aumento no aprendizado. Esse aumento pode ser justificado por alguns aspectos como o esclarecimento de aspectos do problema, visualização de cenário em ambiente interativo, ou até mesmo a criação de um ambiente mais convidativo para as práticas propostas.

\section{Referências}

BARBOSA F. J; FONSECA S. F. Jogos educativos em dispositivos móveis como auxílio ao ensino da matemática Renote, Rio Grande do Sul, v.11 n.1 2013. Disponível em: <http://seer.ufrgs.br/renote/article/view/41623>. Acesso em: 13/09/2013. 
CORREIA, C. A; OLIVEIRA R.L; MERRELHO, A; MARQUES A; PEREIRA D.J; CARDOSO, V. Jogos digitais: possibilidade e limitações o caso do jogo Spore. Cied. 2009. Disponível em: < http://hdl.handle.net/1822/10174>. Acesso em: 14/09/2013.

FORBELLONE, A.L.U; EBERSPÄCHER, H.F. Lógica de programação.São Paulo.Pearson Education Mazion Books. 1999.

GIL, A.C. Métodos e técnicas de pesquisa social. Atlas, São Paulo. Ed 6. 2008.

GONÇALVES, F. E. R. Jogo digital para o ensino dos fundamentos da programação.

Renote, Porto, Portugal. Disponível em:

$<\mathrm{http}$ //sigarra.up.pt/feup/pt/teses.tese?P_ALUNO_ID=20918\&p_processo=803>.

Acesso em: 24/09/2013

GRÜBEL, M.J; BEZ. F. Jogos educativos. Renote, Rio Grande do Sul, v.4 n.2 2006.

Disponível em: <http://seer.ufrgs.br/renote/article/view/14270>. Acesso em: 13/09/2013.

MENDES, G. T. Lume. 2011. Disponível em: $<$ http://www.lume.ufrgs.br/bitstream/handle/10183/61009/000860539.pdf?sequence=1 $>$ . Acesso em: 18/09/2013

PÁRIS, D. P. C. Jogos educativos multimédia: o caso do "Jogo das Coisas". RCAAP, Tese de mestrado. Tecnologia Multimédia. Faculdade de Engenharia. Universidade do Porto. 2009. Disponível em: $<$ http://www.rcaap.pt/detail.jsp?id=oai:run.unl.pt:10362/9916 >. Acesso em: 17/09/2013.

PEIXE, P. I. R; ANSELMO, J.S; MEDEIROS I. L; OLIVEIRA C. Jogo Educativo Para Ensino E Aprendizagem Da Linguagem De Libras: Uma Abordagem Do Design Social Renote, Rio Grande do Sul, v.11 n.3 2013. Disponível em: $<$ http://seer.ufrgs.br/renote/article/view/18080>. Acesso em: 13/09/2013

RAMOS, C. D. Jogos Cognitivos eletrônicos: Contribuições aprendizagens no contexto escolar. Revista Ciência e Cognição. Vol. 18. 2013.

RAPKIEWICZ, E.C; FALKEBACH G; SEIXAS, L; ROSA, N.S; CUNHA, V.V; KLEMANN, M. Estratégias Pedagógicas No Ensino De Algoritmos e Programação Associadas Ao Uso De Jogos Educacionais. Renote, Rio Grande do Sul, v.4 n.2 2006. Disponível em: <http://seer.ufrgs.br/renote/article/view/14284>. Acesso em: $14 / 09 / 2013$.

ROCHA, S.P; FERREIRA, B;MONTEIRO, D; NUNES, C. S.D;GÓES, N. C. H. Ensino e Aprendizagem de Programação : Análise da aplicação de Proposta Metodológica Baseada no Sistema Personalizado de Ensino. Renote, Rio Grande do $\begin{array}{lllll}\text { Sul, } & \text { v.8 } & \text { n.3 } & 2010 . & \text { Disponível }\end{array}$ $<$ http://seer.ufrgs.br/renote/article/view/18061/10649>. Acesso em: 20/09/2013.

RUDOLF, D. B. Pesquisa de satisfação dos clientes da CELESC de Ibirama. Universidade do Estado de Santa Catarina. Departamento de Ciências Contábeis do Centro de Educação Superior do Alto Vale do Itajaí. Curso de Administração de Empresas. Ibirama. 2007.

SAMPAIO, N. E. B. Epik: plataforma para desenvolvimento de jogos para aprendizagem colaborativa e interativa. UNL,2013. Disponível em: $<$ http://run.unl.pt/handle/10362/9916_>. Acesso em: 01/09/2013. 
TAROUCO, L; BERCH, M. O uso de mobile learning no ensino de algoritmos. Renote, Rio Grande do Sul, v.7 n.3 2009. Disponível em: $<$ http://seer.ufrgs.br/renote/article/view/13573>. Acesso em: 17/09/2013. 